\title{
Neoliberalism, Pro-ana/mia Websites, and Pathologizing Women: Using Performance Ethnography to Challenge Psychocentrism
}

\author{
NICOLE D. SCHOTT \\ University of Toronto, Canada \\ LAUREN SPRING \\ University of Toronto, Canada \\ DEBRA LANGAN \\ Wilfrid Laurier University, Canada
}

\begin{abstract}
Key terms such as "pro-ana," "pro-anorexia," and "pro-ED" are searched for on the Internet over 13 million times annually. These searches lead to web pages and social media sites where pro-anorexia and "pro-bulimia" (proana/mia) contributors share weight-loss and exercise tips, "thinspiration" slogans, images and videos, and speak openly about their problems with eating and body image. In this article, we outline our initial research on online responses to proana/mia, and describe how we used the data and analyses from this research to create a piece of research-informed theatre, or performance ethnography. The initial research identified a range of responses to pro-ana/mia that were aligned with either dominant or critical discourses on the causes of, and solutions for, proana/mia. Our findings and analyses challenge media portrayals and medical approaches to pro-ana/mia phenomena, and support an alternative, critical analysis of how psychocentrism and neoliberalism foster social injustices for women and girls. Our work nurtures collective efforts to displace dominant ideologies and practices that have serious implications for the socio-cultural, economic, physical and mental health of women and their communities.
\end{abstract}

KEYWORDS arts-based research; eating disorders; performance ethnography; proana/mia; psychocentrism; social injustice, pathologization 


\section{Introduction}

Hundreds of online fora provide opportunities and spaces for communities of individuals, particularly girls and women, to discuss and communicate about their challenges and problems with eating and body image. Many creators and users refer to these sites, and themselves, as "pro-ana" and/or "pro-mia" (short forms for pro-anorexia and pro-bulimia) (Brotsky \& Giles, 2007). On these fora, contributors share weight-loss and exercise tips, "thinspiration" slogans, images and videos, and speak openly about their successes and their problems. In recent years, pro-ana and pro-mia (hereafter referred to as "pro-ana/mia") have moved from private and public website spaces to social networking sites such as Tumblr, Instagram, Facebook, Pinterest and Twitter, resulting in easier access and more public exposure. Key terms such as "pro-ana," "pro-anorexia," "pro-ED," "prothinspo" and "pro-acceptance" are searched for more than 13 million times annually through the search engine, Google (Lewis \& Arbuthnott, 2012). The growth of pro-ana/mia and its movement to more public spaces online have fueled the perception of a dangerous and out-of-control social problem. In fact, some have argued that pro-ana/mia is one of the new psychopathologies of the 21st century (Starcevic \& Aboujaoude, 2015). This claim conveys the idea that pro-ana/mia websites are the cause, or "trigger" for disordered eating problems (Christodoulou, 2015; Custers, 2015; Pollack, 2003). The media's messaging supports this claim, which is evident in Canadian newspaper article headlines, such as "Online anorexia: Popular 'predatory' websites support perceptions" (Windsor Star, 2006). The media both sensationalizes and oversimplifies women's experiences with eating disorders, most often painting those involved with pro-ana/mia as dangerous, disgusting, abnormal, mentally ill, and in need of expert intervention.

Over the past 15 years, pro-ana/mia has been targeted with censorship (Ferreday, 2003) and these calls have been strongly supported and promoted by medical and mental health professionals across North America, the UK, Italy and France (Schott \& Langan, 2015). Social media sites such as Tumblr, Instagram and Pinterest have been monitoring, banning and deleting pro-ana/mia related interactions and targeting proana/mia individuals with public service announcements that recommend seeking "expert help" (Duca, 2013; Schott \& Langan, 2015). Furthermore, countries such as France and Italy have been proposing restrictive legislation that, if passed, would criminalize individuals within the proana/mia community by imposing huge fines and/or imprisonment (Arnold, 2014; Lichfield, 2008). The media reinforces this direction through headlines like "Eating disorder websites are 'killing people,' experts say" (Bignell, 2007).

This article describes our ongoing sociologically-informed research on pro-ana/mia and responses to it in online pro-ana/mia communities. Guided 
by Charmaz's (2006) grounded theorizing, Hine's (2005) virtual ethnography approach, and poststructural feminism, our initial research revealed the complex voices of pro-ana/mia individuals and myriad responses to these. These data and the historical and critical scholarly literature informed our analysis of how medical and media approaches to pro-ana/mia promote psychocentrism - the idea that all human abnormality is a result of individualized mind or body pathologies (Rimke, 2003; Terry \& Urla, 1995). We developed an alternative interpretation of pro-ana/mia phenomena by interrogating and exposing the psychocentricity of neoliberal conceptions and practices that ignore the social contexts of eating and body image struggles. Guided by the tenets of feminist actionoriented research to highlight the role of social injustices and our commitment to nurturing critical consciousness around eating and body image struggles, we extend the research by using the methodology of performance ethnography to communicate our research findings and analyses. As a continuing project, at each performance we gather audience feedback data that shape our unfolding analyses and subsequent iterations of the performances used to disrupt dominant discourses.

This article contributes to the critical literature on eating and body image issues. Specifically, we share an alternative way of responding to eating and body image issues through using theatre to stage critical analyses. As researchers, artists and women who have struggled with eating and body image, our objective is to ignite social activism that draws attention to, disrupts, and changes the dominant and problematic characterizations of pro-ana/mia and the social contexts that contribute to struggles around eating and body image.

\section{Literature Review}

\section{Dominant Analyses}

Toronto's National Eating Disorder Information Centre (NEDIC), The Canadian Mental Health Association (CMHA), Canada's Center for Addiction and Mental Health (CAMH), and other medical authorities define "anorexia nervosa," "bulimia nervosa," "binge eating disorder" and "eating disorders otherwise not specified" as "clinical" eating disorders. From a medical perspective, a diagnosis of a clinical eating disorder is a recognized medical condition that typically is understood and responded to as a "mental illness." People with eating disorders are frequently cited as having the highest mortality rate of anyone with a Diagnostic and Statistical Manual of Mental Disorders (DSM) diagnosis (Canadian Mental Health Association, 2015).

CMHA (2016) explains that people with anorexia may "refuse to keep their weight at a normal weight" through food restriction or "exercising 
much more than usual." Further, both CMHA and CAMH explain that anorexia nervosa is characterized by a distorted body image, an intense and irrational fear of becoming or being fat, and a strong determination to lose weight. Similarly, both CMHA and CAMH characterize someone with bulimia as having episodes of binge eating, followed by purging.

NEDIC's website describes people who have a clinical eating disorder as being obsessed with controlling their eating to the point of starvation, as a way to achieve a sense of control over their lives. It provides extensive information about anorexia, bulimia, and treatment options. Like CMHA and CAMH, the overarching theme in NEDIC's information is that eating disorders are psychiatric illnesses as seen in individual abnormalities that require treatment by experts.

\section{Historical Analyses}

Historical analyses of eating problems trace how understandings of this topic have changed over time, depending on social and cultural contexts. For example, Brumberg $(2000,46-47)$ has chronicled how the meaning of the anorexic has evolved "from sainthood to patienthood." For medieval women, anorexic fasting - even to the point of death - reflected female holiness. Later, in the $19^{\text {th }}$ century, Victorian anorexia was seen as a manifestation of female hysteria, an individual pathology, attentionseeking, and moral and family failings (Brumberg, 2000). During that century, some medical professionals began to blame anorexia on women's new involvement in higher education, linking anorexia to intellectual activity (Brumberg, 2000), and reflecting the broader power of male psychiatry (see Smith, 1990, for a more detailed analysis).

The rise of psychoanalysis brought an appreciation for women's language, thoughts, and dreams, seen as codes to be interpreted. According to Burstow (2015, p. 85), "Talk and insight - not oversight - was the order of the day. However sexist and scripted the interpretations... the patient was being listened to." While psychoanalysis spawned the move away from the medical model and towards talk-therapy, it also introduced the idea that "virtually everyone could be 'legitimately' viewed as 'having' a 'mental illness"” (Burstow, 2015, p. 121). In an effort to retain their professional turf, psychiatrists, big business and pharmaceutical companies reacted against the rise of psychoanalysis by funding research into the brain, and developing (largely unproven) theories that focused on "chemical imbalances" as the cause of mental illness - a disorder that required "professionalized" treatment (Burstow, 2015). Brumberg (2000, p. 245) traces how, starting in the 19th century, the medical concern for obesity grew and "many internalized the notion that the size and shape of the body was a measure of self-worth." The body became "an instrument of competition, a way to demonstrate one's mettle" (Brumberg, 2000, p. 252), 
spawning an explosion of the diet industry that continues today. Within this context, anorexia has come to be understood as a "condition involving the control of appetite rather than loss of it" (Brumberg, 2000, p. 228).

\section{Critical Analyses}

The critical scholarly literature rejects the dominant approach based on the individualization of eating disorders, and attends to the broader social contexts in which these occur. Blaming pro-ana/mia websites is seen to deflect accountability from the mainstream messages of socially acceptable media and advertising outlets (Boero \& Pascoe, 2012) that promulgate "Western beliefs that thinness is a desirable, beneficial and value enhancing attribute for women" (Knapton, 2013, p. 467). As Walters, Adams, Broer and $\mathrm{Bal}(2015$, p. 10) note, eating disorders represent a self-care "tool" for furthering self-actualization and self-surveillance, laudable goals within a "self-improvement culture." Some critical analyses have examined the complex and contradictory positioning of pro-ana/mia contributors. For example, while some see their eating disorder as a "skill" that makes them superior, talented, hardworking, determined, disciplined, powerful and in control (Walters et al., 2015), others voice self-loathing comments about being "an imperfect person" (Bates, 2014, p. 194). Gailey (2009) has argued that an eating disorder is a voluntary and skilled risk-taking activity that is akin to the predominantly male risk-taking involved in extreme motorcycle racing; the only difference is how society responds to the anorexic versus the motorcycle racer when the risk-taking is lifethreatening: "The man will be treated and released; the woman will be sent to the psychiatric ward or the hospital until she gains 'enough' weight and has shown that she is 'recovered"' (Gailey, 2009, p. 105). This highlights one important characteristic of psychocentrism: it uses a double standard to deal with high-risk behavior privileging one gender over another and thus contributing to sexist medical practices.

Some critical feminist analyses have conceptualized eating disorders as indicative of a rejection of imposed markers of good femininity. Grey (2011) argues that "eating disorders became a projected site for the enactment of women's struggle for independence." Some analyses have underscored the inherent contradictions in medical interpretations of anorexia. For example, Rimke (2000) highlights how in neoliberalism the construction of hyper-responsibility is a population management technique that produces the illusion of autonomy, while actually decreasing autonomy by promoting expert intervention. Others have made the case that this diagnosis has paternalistic and disabling outcomes. As Kendall (2014) noted, even though anorexia arguably represents the most "successful" control over one's appetite, women with anorexia are portrayed as having lost control, and told they need expert intervention and force-feeding to 
gain control over their lives. Some feminist critiques highlight the potentially positive functions that pro-ana/mia websites serve, such as providing multiple forms of support, catharsis and coping mechanisms, reducing feelings of isolation, encouraging recovery, and offering a safe space to promote or challenge disordered eating ideologies and behaviours (Casilli, Tubaro, \& Araya, 2012; Gailey, 2009; Schott \& Langan, 2015; Tubaro \& Mounier, 2014; Wooldridge, 2014). From this perspective, the censoring of pro-ana/mia websites is seen as an extension of the patriarchal control of women (Schott \& Langan, 2015).

\section{Initial Methodology}

The research methodology has been informed by a combination of constructivist grounded theory (Charmaz, 2006), virtual ethnography (Hine, 2005), and liquid ethnography (Ferrell, Hayward, \& Young, 2008). We use an inductive approach that begins with an immersion in the data and moves toward a theoretical analysis "to work from the ground up..." (Charmaz, 2006, p. 21). By combining these methodologies into what Nicole Schott refers to as "a grounded virtual liquid ethnography," a researcher can take into account the transitory and destabilizing characteristics that appear when the line between online and offline interactions are blurred (see Schott \& Langan, 2015, for a detailed description of the method).

Over the past three years, guided by poststructural feminism, Nicole has been immersed the online pro-ana/mia data, her initial focus being on social media sites Tumblr and YouTube. Her immersion was non-intrusive in that she did not interact with those who were posting online; rather, she observed what was taking place online. Further, her immersion moved between and often occurred simultaneously in both online and offline public spaces. As a woman living in Toronto, she was unwittingly bombarded with everyday media representations and narratives about women's bodies, at home, on the street, on public transit, etc. She came to appreciate the connections between the pro-ana/mia interactions she was observing online and the broader socio-political contexts in which she and pro-ana/mia girls and women exist. Picking up on these cultural messages and images, she continually struggled with what experts refer to as "disordered" eating and body image issues. She became painfully aware that there are very few days when she is not exposed to weight loss advertisements and models who have been airbrushed to "desirable," yet unachievable, body sizes and proportions. Nicole came to understand that, like her, pro-ana/mia members are enveloped in thin-privileging and fatphobic environments in their day-to-day experiences.

Throughout her immersion in the data, Nicole produced analytic memos that identified concepts and analyses that emerged through becoming deeply or "intimately" familiar with the data (Lofland, 1971, p. 87). In 
addition, Nicole made field notes on observations and critical selfreflections of those observations, thereby generating additional data on her own experiences with eating and body image phenomena. The memos and field notes provided an important thought-process road map that was central to the conceptualization and articulation of the emergent analyses.

\section{Responses to Censorship}

The initial findings of this research project illustrate the complex nature of online interactions around pro-ana/mia and the various responses that aim to "deal" with these (Schott, 2014). For the purposes of this article, we focus on one dimension of those research findings: the ways in which online participants responded to Tumblr's decision to shut down and/or censor the pro-ana/mia websites. Tumblr is a popular social media blog site that is frequented by many pro-ana/mia girls and women, although we cannot state the gender of individual users with certainty. In 2012, under pressure from eating disorder associations, "recovered" anorexics, their family members and others, Tumblr announced that it was going to shut down all pro-ana/mia and other "self-harm" websites. This decision sparked impassioned and diverse responses online, and our analysis revealed respondents' investments, to varying degrees, in either critical or dominant analyses of the censoring.

\section{Critical Analyses}

Many who spent a great deal of time on these sites reacted with desperation, and their responses suggest an alignment with critical analyses in that they saw the sites as a venue that was helpful to those struggling with eating and body image issues. For example, one blogger said:

PLEASE!!!!!! Don't activate the new policy against self-injury blogs! I literally beg you not to because there have been some AMAZING blogs, that may contain self-harm in them, BUT GIVE AMAZING ADVICE and have been helping me find alternatives and helping me... And I've been able to understand tons of people, and give advice, and get help, and know that I'm not the only one struggling with problems. PLEASE PLEASE PLEEEEEEEEEEEEEASE! Don't delete/ban/trash/block any self-harm, ana/mia, suicide or similar blogs. Please.

Others who were aligned with critical analyses declared Tumblr's actions to be unjust and sexist:

It's not a secret that this new rule will target primarily women. Sick women that have finally found a community where they don't feel alone...This is 
shutting down a community where people can talk openly without addressing the [actually evil] blogs that may have caused them to be where they are.

In a similar vein, another person stated, "it is strange how shit that female people are more likely to do needs this sort of action, but racism, sexism, homophobia, or pornbots... well... hrm."

\section{Dominant Analyses}

Other on-line persons who responded to the threat of shut-down, many of whom claim never to have had eating disorders themselves, supported the eradication of pro-ana/mia sites, and saw these sites as disgusting, promoting a perspective that aligns with popular cultural discourses on women's thinness. As one individual said: "Couldn't agree more ProAnorexia is absolutely disgusting and shouldn't be endorsed by anyone, one of the things that really gets me angry. :/ x." Also in keeping with dominant discourses, many responders stressed the dangerous, harmful and "triggering" effects of pro-ana/mia. According to one person: "the whole 'reblog' feature of tumblr makes self-harm/pro-ana/etc. blogs particularly insidious, because it provides that community/social encouragement towards harming yourself." Many people describe the numerous physical consequences of eating disorders, including death, such as the person who expressed: "...so disappointed in what Tumblr has become, you're basically supporting suicide, honestly..."

Other similar, passionate reactions that were in keeping with dominant discourses came from girls and women who considered themselves in the process of "recovering" from eating disorders (Nicole dubbed them "pissed-off ranters" in her original research). Many statements that supported Tumblr's censoring were like the following:

There's way too much celebration and acceptance of disordered eating here. Personally, I went through a period in college when I threw up all my food. So, when I see blogs with bulimia tips and tricks, I know how much they would have messed me up if they were available back then. Sure, they'll be available elsewhere, but it's nice to see Tumblr confront the fact that they have been inadvertently fostering a community of sickness.

\section{Grounded Theorizing}

Using combined methodologies demonstrated the significance of the online environments for pro-ana/mia individuals, thus highlighting the importance of social contexts that also required analysis. Specifically, Nicole's immersion in the online data, in concert with her everyday life experiences, brought her to the realization that she needed to theorize features of the 
broader culture in which pro-ana/mia was taking place in order to make sense of the individuals, and their interactions, that she was seeing online. She was struck by the juxtapositioning of images that she would see on the pro-ana/mia websites (e.g., pictures of extremely thin girls and the "thigh gap") and the same kinds of images on public billboards (e.g., pictures of emaciated models and the thigh gap). These observations inspired her to become well-versed in contemporary scholarly analyses of culture in order to theorize what was going on. Consequently, the concepts of psychocentrism, neoliberalism, and social injustice came to inform our analysis.

\section{Psychocentrism}

Rimke $(2003,2011)$ has defined psychocentrism as the view that all human "abnormality" is a result of individual mind or body pathologies, noting the "pathological approach" to making sense of human beings as either biologically and/or psychologically "normal" or "abnormal" is a recent phenomenon that is specific to Western culture, perpetuated by the powerful authority of human sciences and the subsequent adoption of "psy" discourses in everyday life (Rimke \& Hunt, 2002; Rimke \& Brock, 2012). Terry and Urla $(1995$, p. 3) make the case that "Scientific and popular modes of representing bodies are never innocent but always tie bodies to larger social systems of knowledge production and, indeed, to social and material inequality."

Psychocentrism renders all areas of human life "knowable," "medicalizable" and "categorizable," and therefore treatable or at least able to be "improved." Rimke and Brock (2012, p. 195) argue that we take for granted "the notion of 'the self' as knowable and as a work in progress." Human scientific authorities are seen as the established psy experts (Rimke $\&$ Hunt, 2002), and the scope of what constitutes a clinical eating disorder is now more broadly medicalized than ever before. For example, additional types of diagnoses have been added to the DSM such as "eating disorders not otherwise specified" and "binge eating disorder" (American Psychiatric Association, 2013).

\section{Neoliberalism}

David Harvey defines neoliberalism as a theory of political economic practices that proposes that human well-being can best be advanced by individual entrepreneurial freedoms and skills $(2007$, p. 2). Neoliberalism's emphasis on the significance of the individual is legitimated and reinforced by psychocentrism. Psychocentric discourses posit that humans can achieve "true happiness" through learning about themselves through "hard work," 
"moral goodness" and "self-government" (Binkley, 2015; Rimke \& Brock, 2012); the emphasis is on neoliberal citizens becoming "hyperresponsibilized" subjects, who are to be accountable for all of their successes and failures (Rimke, 2000).

Neoliberal discourses are advanced, for example, through marketing strategies that promote control over one's body, conflate thin bodies with positive personality traits and late-modern definitions of what it means to be a successful woman or a "good citizen" (Bordo, 2003; Schott, 2015). Often in pro-ana/mia interactions, as in popular culture, skinny is articulated as "perfection" which is achieved through "choice," "selfcontrol," "strength" and "hard work." It follows that within neoliberal culture, people will go to extremes to control their appetite, often with the "help" of consumer goods such as weight loss, anti-aging and cosmetic products. But, as Rimke and Brock (2012) argue, the pursuit of perfection always leads ultimately to failure because the psychocentric regime of modern capitalism does not allow anyone to ever become "good enough."

Capitalist enterprise has benefited handsomely from supporting people's failed attempts to, ironically, gain "self-control," attain the "right" body, and eat and exercise "responsibly" (Rimke, 2000; Rimke \& Brock, 2012). According to Global News and the Vancouver Sun (Ellis, 2013a, 2013b), Canada's weight loss industry is worth seven billion dollars and each year, and since the 1980s weight loss sales have been increasing six percent across North America. Thus, the popularized feminine body image and widespread dissatisfaction with it, is reinforced through marketing practices that benefit the hierarchies, victim-blaming, and double standards of capitalism and patriarchy.

\section{Social Injustice}

By understanding how psychocentrism goes hand in hand with neoliberal ideologies that fuel the unachievable quest for individual perfection, we can understand how eating disorders are driven by the cultural contexts in which they develop and are sustained. When dominant analyses attribute eating disorders to the individual failings of women and girls, they become positioned as "crazy," "hysterical," "emotional" and "irrational." Even for women and girls who have not been diagnosed with an eating disorder, these dominant ideologies perpetuate their struggle to achieve the perfect bod, again an unattainable goal. As a result, subjectivities of insecurity are fostered among women and girls, a situation that contributes to unequal gender power relations; not only do women and girls - with or without eating disorders - devalue themselves, but they are also socially devalued when they fall short of perfection. These outcomes combine with other social factors to exacerbate social inequalities between women and men, and thus hinder the goals of gendered social justice. 


\section{Research Outcome: Performance Ethnography as Methodology}

The lack of recognition of, and accountability for, the social and gendered contributors to eating problems have inspired us to work toward progressive social change through a research-informed theatre project or performance ethnography. Many researchers, over the past few decades, have come to view theatre as a powerful tool to analyze data and share research findings (Rossiter et al., 2008). This approach is seen as an engaging and potentially more "meaningful, accessible, and challenging" way of sharing qualitative and quantitative data (Gray, 2011, p. 64). Norman Denzin (2003, p. 111), who has published widely on qualitative and ethnographic research, argues that performance ethnography has the potential to "intervene and interrupt public life," and that "such interruptions are meant to unsettle and challenge taken-for-granted assumptions concerning problematic issues in public life. They create a space for dialogue and questions, giving voice to positions previously silenced or ignored."

As Goldstein (2012) points out, performance ethnography as a method is inextricably linked to the literary turn in American anthropology that began in the 1980s. With the realization that "ethnographers invent rather than represent ethnographic truths" came the added responsibility on the part of researchers to become self-reflexive, and conscious of their own positionality and the inherent limitations of research that seeks to represent others (Goldstein, 2012, p. 3). As researchers have become more aware of their own power, biases and privileges (Goldstein, 2012), questions have arisen about who benefits from the research (Madison, 2012, p. 8). Because performance ethnographies strive to offer a multiplicity of perspectives that can lead to radical transformations in thinking, playwrights tend to ask "really good questions" rather than provide "right answers" with their work (Snyder-Young, 2010, p. 891).

In our performance ethnography, we use our data and analyses as source materials for the purpose of bringing academic research to life by creating what Madison (2012, p.10) refers to as a "dialogic performance" or a "meeting of multiple sides." We want to provide audience members with an opportunity to engage with the research questions and findings on both intellectual and emotional levels, more viscerally than if they were to simply read about the research in an academic journal. As noted by Rossiter et al. (2008), the "embodiment" of data holds "particular potential" for health research that deals with complicated issues related to individual subjectivity.

Our performance ethnography incorporates insights from our abovenoted findings and our critical analyses. Public presentations of our play create a visual, interactive, social space to emphasize and engage with others about critical social problems and analyses that explore the ways in which society valorizes thinness, is marked by race, class and gender 
inequalities, and fails to provide helpful options for girls and women who live with the struggles of eating and body image issues.

\section{Researcher Positionality}

Committed to the social justice principles of action-research, as our project developed we chose performance ethnography to work toward ideals of progressive social change. The second author of this paper, a playwright and researcher Lauren Spring, began collaborating with first author Nicole Schott after the above-described initial analyses had been completed. At age 16, Lauren was diagnosed with anorexia and - against her will - spent several months as an inpatient at a treatment facility in Ontario. The treatment Lauren received as an inpatient, like many others still receive today, is strikingly similar to what girls and women experienced throughout the $1800 \mathrm{~s}$. According to Lauren's experience, the ultimate objective remains steady weight gain through often violent force feeding. Release dates from eating disorder wards of public hospitals are based primarily on weight targets being met. Individual reasons for self-starvation are rarely explored in institutional settings, which likely contributes to dramatic weight loss once released, leading individuals to repeatedly return to the clinical programs as sick patients.

\section{Developing the Performance}

The focus of Lauren's and Nicole's collaboration has been on transforming Nicole's research on pro-ana/mia into a performance ethnography. Currently, the first 20 minutes of the play have been developed, and it has been workshopped twice in public settings, once as a course presentation at the University of Toronto, and again at a critical disability conference. To begin, Lauren immersed herself in numerous pages of empirical material collected by Nicole, her Master's thesis and other papers on pro-ana/mia. After Lauren had become completely saturated in Nicole's work, she began transforming Nicole's original material into a play script, using the research findings to create composite characters that consisted of both verbatim and "imagined" lines of dialogue. Although some performance ethnographers create "verbatim" plays (i.e., the script only consists of words actually spoken during interviews), many opt to stray somewhat from verbatim data while remaining true to the information and themes gathered during the research process (e.g., Denzin, 1997; Gray \& Sinding, 2002; Rossiter et al., 2008; Saldana, 2005). They create instead a fictional character that is a composite of several interviewees, for example, or use metaphor, symbolism and physical expression to "stay true to the essence" of the research data - in an effort to 
create more "authentic" communication (Gray, 2009, p. 3-4). Denzin (1997, p. 100) argues that this approach is in keeping with the critical ethnographic objective to contest singular truth and linear narratives, display a multiplicity of perspectives, and inspire cultural critique.

Once the first two scenes were produced, Nicole reviewed the script and provided feedback. We named our main pro-ana/mia character "Ana" because pro-ana/mia community members often personify their eating disorder by referring to "her" as Ana. In the original version, Lauren had opted to open the play with the character of Ana sitting at a computer recording a video about her exercise tips for her pro-ana YouTube channel and its followers. While very powerful, aesthetically speaking, Nicole suggested that since a primary objective of the play is to disrupt the current narrative that eating disorders are a result of individual pathology, it made more sense to open the play in a more social context, to reveal the normalization of equating weight loss with ideas of control, willpower and success for women and girls, not to mention beauty and sex appeal. Additionally, she recommended scripting-in popular media culture, such as the Britney Spears music video "Work Bitch" that conflates high social status with a "hot body" and an ardent work ethic. It was decided to contextualize pro-ana/mia in these ways in order to produce provocative juxtapositions throughout the performance. Nicole's suggestions, and the subsequent script re-writes they inspired, revealed that staging the descriptive findings was not enough; it was also vital that Nicole's critical theorizing be represented in the play, wherever possible.

As our research continues, we will present the play to specific groups of stakeholders (e.g., girls and women living with troubled eating; physicians, doctors, counselors and nurses involved in their care; family members of individuals diagnosed with eating disorders; public school teachers). Our research project will continue to solicit informal audience feedback to inform future drafts of the script, through question and answer discussions, written questionnaires, and one-on-one conversations with audience members who approach us to share their feedback. Some open-ended questions we ask audience members include: How do you feel after watching this play?; Was it realistic?; Which part of the play was most memorable for you?; Why?; What, if anything, is missing from this play? The feedback to date confirms the important role that the performance plays in transformative learning, an outcome that is ultimately connected to social justice and change (Kokkos, 2010).

\section{Staging Stories}

For the purposes of this article, we attend to how we stage the story of the women's responses to Tumblr's censorship policy. Lauren opted not to explicitly address Tumblr's policy in the play, but rather to represent its 
attempts at muzzling expression symbolically. The main character, Ana, who has recently been discharged from inpatient treatment, has been made to promise that she will no longer visit or post on pro-ana websites because the authority figures in her life (her doctor, mother and brother) view them as dangerous. Ana, however, continues to post on these sites because they represent an important community for her. When it is discovered she is doing this, a passionate argument ensues where three characters on stage engage in a debate using both critical and dominant perspectives. For example, Ana's brother Jeff, who finds her exercising in her room and posting on YouTube at 5 a.m., embodies the disgust many online commenters express.

JEFF: Ana, it's not normal to be doing sit-ups on your bedroom floor in the dark while the rest of the world is still asleep.

ANA: It's not my fault if the rest of the world is lazy.

JEFF: That's right Ana. It's the rest of the world that's crazy. You're the normal one. You are sick. You know that? You are sick and I'm going to tell mom and she'll put you in the hospital again because that's where you belong. I don't know why they let you out.

Later in the scene he says:

JEFF: And look, mom. She's on her stupid Tumblr again. Posting stupid videos of her stupid puny face trying to convince other girls to make themselves as sick as she is. It's disgusting. This whole thing is just so sick. It's so sick.

Ana herself insists that she knows what she is doing, and is very critical of why she continues to be blamed, and her behaviour pathologized.

ANA: You know what's fucked up? You both treat me like I'm some sort of criminal. I'm not. Why don't you go after the racists out there? There are horrible people. There are racist and homophobic and misogynistic people out there, and they're allowed to express themselves however they want online. Why do you let them off the hook? You think I'm the problem?

Above, Ana emphasizes the double standards of social control, its result, social inequalities and the effects, social harm. Ana also expresses later in the scene how unhelpful "treatment" was for her. In the second scene of the play, Ana's mother (Cathy) shares the "pissed-off ranters" faith in traditional biomedical treatment, reprimands Ana for not following the doctor's orders, and threatens to send her back to the hospital. Cathy loves her daughter deeply, and as a woman understands her body image suffering in a way that gender-privileged Jeff does not. Cathy reacts emotionally to finding her daughter engaging in pro-ana behavior. Many audience members following our two performances have said that they identified 
with Cathy's feelings of helplessness: that she does not want Ana's suffering to continue, but has nowhere else to turn and nothing else to offer except what the doctor says is best.

MOTHER: If you fall under 75\% of your ideal bodyweight again, you're not going to have a choice. You know that. Doctor Blume will make you an inpatient again. Is that what you want? Are you trying to get yourself admitted to the hospital again?

ANA: Of course not!

MOTHER: It might not be the worst thing, Ana... They can help you.

ANA: Oh Yah? How? By sticking a tube down my throat to force feed me? By restraining me in a bed? By making me stand on the scale at 6 a.m. every morning just to torture me as I see the numbers go up and up and up? By making me pee into a plastic measuring cup so they can keep track of every last ounce of liquid that enters into and exits my body? Because that's what they do there. You think that's helpful? They don't help anything. They don't do shit!

\section{Aesthetics}

During the writing and staging process, Lauren had to make a number of important aesthetic choices to ensure the play captured not only words spoken and written online, but also the "extralinguistic" aspects of collected data: tone of voice, actions, etc. (Conquergood, 2002, p. 147). It was also important to find a way through movement, lighting, and other technological conventions, to show the blurring of online and offline spaces in order to capture Nicole's virtual liquid methodology. We demonstrate this complexity in numerous ways, including having "pop-up" ads spoken by recorded off-stage voices about weight loss commodities interrupt conversations taking place between characters. For example, as Ana is raging with her mother and brother, the pop-up ad on her computer is given a voice: "Do you want to lose 16 kilograms in four weeks? This miracle pill burns fat FAST." Aesthetically, this reveals how disruptive and inescapable pop-up ads can be. Also, as Ana goes through her intense 5 a.m. workout on centre stage, projected on to her body and the screen behind her is an actual thinspiration video from a pro-ana site. Simultaneously, contradicting comments from doctors, weight loss advertisers, pro-ana/mia supporters, thin idealizers and pissed-off ranters are called out by different actors off stage to represent Ana's conflicting thoughts as she tries to lose herself in her workout. The intention of this technique is to make it unclear which messages are from online or offline, which are in internal to her own mind or represent external advice given to her by others, and which are socially acceptable or unacceptable. 
The second scene of the play opens with Ana recording a video for her YouTube channel. Aesthetically speaking, this monologue reflects not only what girls and young women say in such videos on pro-ana/mia sites in real life, but also how they say it. They have rambling speech patterns, repeated and accentuated words, and they go on for an uncomfortably long time. Although in some ways the two page monologue that is Ana's video recording could be edited down, Lauren thought it was more true to the research data and also important for audience members to experience the uneasiness: on the one hand to feel badly for Ana, clearly caught in a difficult and vulnerable situation, while on the other being slightly annoyed by her and her seemingly narcissistic behaviour. As researchers and artists we have made the decision to give Ana the stage, even though her perspective may be somewhat fragmented and contradictory.

\section{Conclusion}

Our theoretical approach "interrogates the assumptions and certainties embedded in our culture's attitudes, beliefs, desires and practices concerning the normal and the pathological" (Rimke \& Brock, 2012, p. 186). We argue that taken-for-granted designations of "abnormal" are a feature of our psychocentric and neoliberal landscape that positions individuals as both the cause and the solution for any suffering that they experience (Rimke, 2000). Our work actively contextualizes pro-ana/mia as a feature of a society that privileges thinness, discriminates against "fat" bodies, and celebrates neoliberal values which promote the individual control over, and improvement of, body weight, size and shape. Like Rimke and Brock (2012, p. 184), our analysis examines "the historical relationship between forms of knowledge, the exercise of power, and the creation of subjects." We argue that online pro-ana/mia spaces need to be retained not eradicated or censored - as they represent meaningful opportunities for women and girls to share their experiences, confront the issues that they face, and find ways to support one another. These spaces also allow those outside pro-ana/mia communities a unique glimpse into contributors' diverse views and opinions - perspectives that are rarely represented in medical literature or by the mainstream media. To disregard how women make sense of their situations is socially unjust; they become constructed as simpletons who are incapable of producing a valid view or decision. Dominant Western culture promotes feminine subjectivities of insecurity, and produces hyper responsibilization of women and girls, in regards to body image and self-worth. These outcomes, in combination, contribute to the maintenance of social inequality in gender relations.

We have demonstrated how performance ethnography can be used as a social justice tool by bringing these injustices to light. In order to break down psychocentric ideologies, members of the public must be able to hear 
the words and perspectives of others. As Chinyowa (2013) suggests, socially constructed "truths" must be un-performed (making reference to Banks, 2006), or deconstructed to allow for the re-imagining of identities that have been artificially, yet powerfully, fixed. We un-perform through showcasing the multiplicity of pro-ana/mia interactions and embedding these within the broader neoliberal landscape.

Our performance stages the narratives of these girls and women in a way that suggests they matter and have something to teach us about how social injustices profoundly impact their lives. We contend that a psychocentric presentation of these data would not have recognized the importance of the passion and injustice pro-ana/mia girls express, and would have "written off" their passion as "hysterics," symptomatic of mental illness. We also demonstrate that the pro-ana/mia community is a very diverse and complicated group of people: the play portrays both desires for recovery and resistance to recovery; the painful struggle that eating disorders cause as well as the pride that comes with pushing an extreme; the self-hatred involved in disordered eating but also the hard work, determination and will-power it takes; the positive coping and expressive outlet pro-ana/mia websites provide alongside the troubling tips, tricks and messages found on those pages.

As our process continues, we are working hard to be as loyal as possible to our research data and analyses while also making bold aesthetic choices to ensure authenticity in the performance. Still, we are also always mindful of our ethical responsibilities as researchers to not engender harm. This position means that we must carefully manage where, when, and how to best depict truths aesthetically on stage. We strive to do this in a way that does not alienate audience members, but helps them better understand the issues, and feel more deeply so that the questions raised by the playwatching experience resonate more meaningfully over time.

We are committed to never losing sight of our pedagogical objectives: to challenge the dominance of the medical model and other societal discourses that pathologize pro-ana/mia supporters, and to provide access to alternative, critical analyses that explore the broader socio-cultural ideologies and practices that underlie pro-ana/mia phenomena. We recognize that we have a responsibility to audience members, many of whom have first-hand knowledge of, and experience with, eating disorders. Although we want our play to have a powerful emotional impact, we are wary of "triggering" vulnerable audience members. Where other events or performances of this nature might have "experts" on site (nurses, psychiatrists) to talk after the show with those who might be troubled by what they have seen represented on stage, this would be inappropriate in our case. Given our critique of the medical model, it would be disingenuous for us to have heath care professionals be the "experts in the room." Instead, to move conversations into a social analysis and education framework, each of our performances will be followed up by a guided 
discussion, facilitated by researchers, feminist psychotherapists, participants, and playwrights where audience members will be given the space to share what they learned from the presentation, what they found beneficial or worrisome, and what they would change or expand, knowing that their responses will have a profound impact on future drafts of the script. Our experiences to date confirm that our performance ethnography is inspiring thoughtful and critical dialogue around difficult questions.

Our research contributes to the literature on, and approaches to, eating and body image issues. Our goal as researchers, artists and women who have struggled with eating and body image, is to ignite activism that draws attention to, challenges, and changes the dominant and problematic characterizations of pro-ana/mia and the social contexts that contribute to struggles around eating and body image. Through staging our critical analyses and orchestrating shared conversations on eating and body image issues, we seek to nurture collective efforts to displace dominant ideologies and practices that have serious implications for the socio-cultural, economic, physical and mental health of women and their communities (Schott \& Langan, 2015). Through performance work, our research can serve as a form of "radical democratic practice" (Denzin, 2001) to foster social change by using performance ethnography to challenge how dominant understandings of, and responses to, these issues perpetuate social injustice.

\section{Acknowledgements}

We want to sincerely thank the online contributors and the audience members at our performances for so generously sharing their insights on eating and body image issues. The first author, Nicole Schott, would like to recognize the support she received through a Lupina Doctoral Fellowship from the Munk School of Global Affairs, University of Toronto.

\section{References}

American Psychiatric Association (2013). Feeding and eating disorders. Retrieved from http://www.dsm5.org/documents/eating\%20disorders\%20fact $\% 20$ sheet.pdf

Arnold, C. (2014, August 30). Should pro-anorexia sites be criminalized? The Daily Beast. Retrieved from http://www.thedailybeast.com/articles/2014/08/30/should-pro-ana-sitesbe-criminalized.html

Bates, C. F. (2014). I am a waste of breath, of space, of time: Metaphors of self in a proanorexia group. Qualitative Health Research, 25(2), 189-204.

Bignell, P. (2007, January 7). Eating disorder web sites are 'killing people,' experts say. The Independent. Retrieved from http://www.independent.co.uk/life-style/health-andfamilies/health-news/proanorexia-websites-are-killing-people-431065.html

Binkley, S. (2015). Happiness as enterprise: An essay on neoliberal life. New York: State University of New York. 
Bordo, S. (2003). Unbearable weight: Feminism, western culture, and the body. Berkeley: University of California Press.

Boero, N., \& Pascoe, C. (2012). Pro-anorexia communities and online interaction: Bringing the pro-ana body online. Body \& Society, 18(2), 27-57.

Brotsky, S., \& Giles, D. (2007). Inside the "pro-ana" community: A covert online participant observation. Eating Disorders, 15(2), 93-109.

Brumberg, J. J. (2000). Fasting girls: The history of anorexia nervosa. New York: Vintage Books.

Burstow, B. (2015). Psychiatry and the business of madness: An ethical and epistemological accounting. New York: Palgrave Macmillan.

Canadian Mental Health Association. (2016). Eating disorders. Retrieved from http://ontario.cmha.ca/mental_health/eating-disorders/\#.VPoHvfnF_2g

Casilli, A., Tubaro, P., \& Araya, P. (2012). Ten years of ana: Lessons from a transdisciplinary body of literature on online pro-eating disorder websites. Social Science Information, $51(1), 120-139$

Charmaz, K. (2006). Constructing grounded theory: A practical guide through qualitative analysis. Thousand Oaks, CA: Sage.

Chinyowa, K. (2013). Interrogating spaces of otherness: Towards a post-critical pedagogy for applied drama and theatre. Applied Theatre Research, 1(1), 7-16.

Christodoulou, M. (2015) Pro-anorexia websites pose public health challenge. The Lancet, 379(9811), 110.

CMHA (The Canadian Mental Health Association). (2016.) Eating Disorders. Retrieved from http://www.cmha.ca/mental_health/facts-about-eating-disorders/\#.V3vNV7grLIU

Conquergood, D. (2002). Performance studies: Interventions and radical research. The Drama Review, 46(2), 145-156.

Custers, K. (2015). The urgent matter of online pro-eating disorder content and children: Clinical practice. European Journal of Pediatrics, 174(4), 429-433.

Denzin, N. (1997). Interpretive ethnography: Ethnographic practices for the 21st century. London: Sage.

Denzin, N. (2001). The reflexive interview and a performative social science. Qualitative Research, 1(1), 23-46.

Denzin, N. (2003). Performance ethnography: Critical pedagogy and the politics of culture. Thousand Oaks, CA: Sage.

Duca, L. (2013, August 28). Can thinspiration really be \#banned from instagram? The Huffington Post. Retrieved from http://www.huffingtonpost.com/laurenduca/thinspiration-banned-from-instagram_b_3829155.html

Ellis, E. (2013a, April 29). Diet industry expands right along with North American waistlines. Global News. Retrieved from http://globalnews.ca/news/519060/diet-industry-expandsright-along-with-north-america-waistlines/

Ellis, E. (2013b, April 26). Diet industry expands right along with North American waistlines - Unregulated industry is a haven for empty promises, experts say. The Vancouver Sun. Retrieved from http://www.vancouversun.com/health/Diet+industry+expands+right+along+with+North +America+waistlines/8268951/story.html

Ferreday, D. (2003). Unspeakable bodies: Erasure, embodiment and the pro-ana community. International Journal of Cultural Studies, 6(3), 277-295.

Ferrell, J., Hayward, K., \& Young, J. (2008). Cultural criminology: An invitation. London: Sage.

Gailey, J. (2009). "Starving is the most fun a girl can have": The pro-ana subculture as edgework. Critical Criminology, 17(2), 93-108.

Goldstein, T. (2012). Staging Harriet's House: Writing and performing research-informed theatre. New York: Peter Lang.

Gray, J. (2009). Theatrical reflections of health: Physically impacting health-based research. Applied Theatre Researcher/IDEA Journal, 10,10pp.

Gray, R., \& Sinding, C. (2002). Standing ovation: Performing social science research about cancer. Walnut Creek, CA: AltaMira Press.

Studies in Social Justice, Volume 10, Issue 1, 95-115, 2016 
Grey, S. H. (2011). A perfect loathing: The feminist expulsion of the eating disorder. $K B$ Journal, 7(2). Retrieved from http://kbjournal.org/grey

Harvey, D. (2007). A brief history of neoliberalism. New York: Oxford University Press.

Hine, C. (2005). Virtual methods: Issues in social research on the internet. New York: Oxford.

Kendall, S. (2014). Anorexia nervosa: The diagnosis - A postmodern ethics contribution to the bioethics debate on involuntary treatment for anorexia nervosa. Bioethical Inquiry, 11, $31-40$.

Knapton, O. (2013). Pro-anorexia: Extensions of ingrained concepts. Discourse \& Society, 24(4), 461-477.

Kokkos, A. (2010). Transformative learning through aesthetic experience: Towards a comprehensive method. Journal of Transformative Education, 8(3), 155-177.

Lewis, S. P., \& Arbuthnott, A. E. (2012). Searching for thinspiration: The nature of internet searches for pro-eating disorder websites. Cyberpsychology, Behaviour, and Social Networking, 15(4), 200-204.

Lichfield, J. (2008, April 15). France bans websites promoting anorexia 'cult'. Independent. Retrieved from: http://www.independent.co.uk/news/world/europe/france-bans-websitespromoting-anorexia-cult-809617.html

Lofland, J. (1971). Analyzing social settings. New York: Wadsworth.

Madison, S. (2012). Critical ethnography: Method, ethics, and performance ( $2^{\text {nd }}$ Ed.). Sage: London.

Pollack, D. (2003). Pro-eating disorder websites: What should be the feminist response? Feminism and Psychology, 13, 246-251.

Rimke, H. (2000). Governing citizens through self-help literature. Cultural Studies, 14(1), 6178.

Rimke, H. (2003). Constituting transgressive interiorities: $19^{\text {th }}$ century psychiatric readings of morally mad bodies. In A. Arturo (Ed.), Violence and the body: Race, gender and the state (pp. 403-428). Bloomington, IN: Indiana University Press.

Rimke, H. (2011). The pathological approach to crime: Individually based theories. In K. Kramer (Ed.), Criminology: Critical Canadian perspectives (pp. 78-92). Toronto: Pearson Education Canada.

Rimke, H., \& Brock, D. (2012). The culture of therapy: Psychocentrism in everyday life. In M. Thomas, R. Raby \& D. Brock (Eds.), Power and Everyday Practices (pp. 182-202). Toronto: Nelson.

Rimke, H., \& Hunt, A. (2002). From sinners to degenerates: The medicalization of morality in the $19^{\text {th }}$ century. History of the Human Sciences, 15(1), 59-88.

Rossiter, K., Kintos, P., Colantonio, A., Gilbert, G., Gray, J., \& Keightley, M. (2008). Staging data: Theatre as a tool for analysis and knowledge transfer in health research. Social Science \& Medicine, 66 (1), 130-146.

Saldana, J. (Ed.). 2005. Ethnodrama: An anthology of reality theatre. Walnut Creek, CA: AltaMira Press.

Schott, N. (2014). Pro-anorexia/bulimia interactions online: Problematizing complex cultural phenomena (Unpublished Masters thesis). Wilfrid Laurier University, Waterloo, ON. Retrieved from: http://scholars.wlu.ca/cgi/viewcontent.cgi?article=2760\&context=etd

Schott, N. (2015). Food marketing as a pedagogical act: Teaching women to consume 'skinny'. Journal of Social Justice, 5, 1-23.

Schott, N., \& Langan, D. (2015). Pro-anorexia/bulimia censorship and public service announcements: The price of controlling women. Media, Culture \& Society, 37(8), 11581175 .

Smith, D. E. (1990). K is mentally ill: The anatomy of a factual account. In D. E. Smith (Eds.), Texts, facts and femininity: Exploring the relations of ruling (pp. 12-52). Oxford: Routledge.

Snyder-Young, D. (2010). Beyond an "aesthetic of objectivity": Performance ethnography, performance texts, and theatricality. Qualitative Inquiry, 16, 883-894.

Starcevic, V., \& Aboujaoude, E. (2015). Cyberchonria, cyberbullying, cybersuicide, cybersex: "New" psychopathologies for the 21st century? World Psychiatry, 14(1), 97-100.

Terry, J., \& Urla, J. (1995) Deviant bodies. Bloomington, IN: Indiana University Press. 
Tubaro, P., \& Mounier, L. (2014). Sociability and support in online eating disorder communities: Evidence from personal networks. Network Science, 2(1), 1-25.

Walters, B. H., Adams, S., Broer, T., \& Bal, R. (2015). Proud2Bme: Exploratory research on care and control in young women's online eating disorder narratives. Health, 1-22, online first.

Windsor Star. (2006, June 5). Online anorexia: Popular 'predatory' websites support perceptions. Retrieved from http://www.canada.com/story_print.html?id=706855dd4cf1-43e9-9ab7-aaad71f7114f\&sponsor=

Wooldridge, T. (2014). The enigma of ana: A psychoanalytic exploration of pro-anorexia internet forums. Journal of Infant, Child, and Adolescent Psychotherapy, 13(3), 202-216. 